\title{
PUSAT INFORMASI TURIS DI KAMPUNG BATIK BABAGAN LASEM BERBASIS ECO-BATIK
}

\author{
Natalia Lie Leonard ${ }^{1)}$, Samsu Hendra Siwi ${ }^{2)}$ \\ 1) Program Studi S1 Arsitektur, Fakultas Teknik, Universitas Tarumanagara, natalialieleonard@gmail.com \\ 2) Program Studi S1 Arsitektur, Fakultas Teknik, Universitas Tarumanagara, samsus@ft.untar.ac.id
}

Masuk: 04-07-2021, revisi: 15-08-2021, diterima untuk diterbitkan: 23-10-2021

\begin{abstract}
Abstrak
Artikel ini meneliti tentang penyediaan fasilitas pengembangan pariwisata di Kampung Batik Babagan sebagai pusat informasi turis. Isu ekologis menjadi konsentrasi dalam penelitian ini. Kampung Batik Babagan merupakan sebuah pusat industri batik rumahan dengan letak rumah produksi batik yang tersebar. Di kawasan ini belum memiliki pusat informasi sebagai wadah bagi turis untuk mendapatkan informasi yang lengkap tentang kawasan Babagan. Pusat Informasi Turis Kampung Batik Babagan Lasem dirancang sebagai solusi arsitektur ekologis dalam menciptakan ekosistem eco-batik dan menjadi wadah untuk mengakomodasi serta mengedukasi turis dan masyarakat mengenai informasi nilai sejarah dan budaya dari kawasan Babagan yang sesuai dengan konteks lingkungan setempat. Diharapkan proyek ini dapat meningkatkan ekonomi masyarakat lokal. Kajian literatur yang digunakan meliputi, arsitektur ekologis, eco-batik, zat pewarna tekstil, dan proses pembatikan di Lasem. Metode penelitian yang digunakan, yaitu metode deskriptif eksploratif, analisis lokasi dan tapak. Dari hasil analisis tersebut, bangunan dalam tapak dibagi menjadi dua massa sesuai dengan fungsi kegiatan di dalamnya. Atap bangunan menggunakan atap jurai sebagai penyesuaian dengan iklim tropis. Bagian interior bangunan didesain agar terjadi interaksi antar pengunjung dan pada eksterior diberi ornamen yang mencirikan Kampung Batik Babagan.
\end{abstract}

Kata kunci: batik; ekologi; edukasi; informasi.

\begin{abstract}
This article examines the provision of tourism development facilities in Babagan Batik Village as a tourist information center. Ecological issues are the focus of this research. Kampung Batik Babagan is a home-based batik industry center with scattered batik production houses. This area does not yet have an information center as a forum for tourists to get complete information about the Babagan area. The Babagan Lasem Batik Village Tourist Information Center is designed as an ecological architectural solution in creating an ecobatik ecosystem and as a forum to accommodate and educate tourists and the public regarding information on the historical and cultural values of the Babagan area that are in accordance with the local environmental context. It is hoped that this project can improve the economy of local communities whose main livelihood is from batik by taking into account the impact on the environment. The literature studies used include ecological architecture, eco-batik, textile dyes, and the batik process in Lasem. The research method used is exploratory descriptive method, location and site analysis. From the results of the analysis, the building in the site is divided into two masses according to the function of the activities in it. The roof of the building uses a jurai roof as an adjustment to the tropical climate. The interior of the building is designed to allow interaction between visitors and the exterior is decorated with ornaments that characterize Babagan Batik Village.
\end{abstract}

Keywords: batik; ecolgy; education; information. 


\section{PENDAHULUAN}

\section{Latar Belakang}

Manusia memiliki kebutuhan pokok mendasar yang terdiri dari kebutuhan sandang, pangan, dan papan. Seiiring dengan perkembangan zaman dan pertumbuhan populasi, kebutuhan manusia semakin meningkat dan beragam. Namun, kebutuhan primer, yaitu sandang, pangan, dan papan masih menjadi hal yang paling utama. Sandang merupakan salah satu kebutuhan primer yang tidak terlalu diperhatikan dampak peningkatannya (Nailufar, 2020).

Pada 2015, setidaknya 100 miliar potong pakaian diproduksi di seluruh dunia dalam setahun. Kebutuhan sandang semakin meningkat seiring dengan bertambahnya jumlah penduduk. Dibalik semua perkembangan dan meningkatnya produksi sandang tersebut, dampak negatif yang dihasilkan dari industri tekstil banyak tidak diketahui dan tidak diperhatikan. Industri tekstil merupakan penyumbang emisi gas rumah kaca terbanyak dan limbah cairan berbahaya di laut (Oktaviani, 2020).

Batik merupakan salah satu cabang seni rupa dengan latar belakang sejarah dan budaya yang erat kaitannya dengan proses produksi sandang. Kerajinan batik tradisional diproduksi dengan teknik manual dan dikerjakan satu persatu mulai dari pemolaan hingga pewarnaannya. Nilai budaya dari batik perlu dipertahankan sebagai identitas bangsa Indonesia. Akan tetapi, seiring dengan perkembangan zaman dan teknologi, teknik pengerjaan batik dapat dilakukan dengan bantuan mesin. Selain itu, pewarna kain yang diambil dari alam, sekarang banyak digantikan oleh pewarna sintetis yang lebih mudah didapatkan. Proses produksi batik dari awal hingga akhirnya menjadi sebuah produk memiliki dampak negatif bagi lingkungan yang tidak terlalu diperhatikan (Setyawan, 2019).

Kampung Batik Babagan yang terletak di Lasem merupakan salah satu sentra industri batik rumahan yang proses produksinya sudah mulai beralih menggunakan pewarna sintetis tanpa diimbangi dengan adanya fasilitas pengolahan limbah tersebut. Disamping itu, Kampung Batik Babagan ini memiliki nilai sejarah dan budaya yang masih kuat dan perlu dilestarikan (Meriastuti, 2018).

Rumah produksi batik dan beberapa tempat wisata serta bersejarah yang tersebar di wilayah Desa Babagan memerlukan sebuah sentra yang dapat menjadi fasilitas pusat informasi bagi para turis yang akan berkunjung ke kampung ini. Kegiatan edukasi mengenai eco-batik, yaitu proses membatik yang meminimalisir pencemaran lingkungan dan kegiatan wisata sejarah dari kampung batik Babagan menjadi program utama dalam proyek ini.

Oleh karena itu, penulis merancang proyek Pusat Informasi Turis Kampung Batik Babagan sebagai proyek yang memfasilitasi kegiatan wisata di tempat ini dan juga diharapkan dapat meningkatkan ekonomi masyarakat yang mata pencaharian utamanya adalah produksi batik dengan pendekatan arsitektur yang melampaui ekologi.

\section{Rumusan Permasalahan}

Sandang, yang merupakan kebutuhan primer manusia memiliki dampak negatif dalam proses produksinya yang semakin meningkat. Batik merupakan salah satu budaya Indonesia yang erat hubungannya dengan proses produksi sandang. Kampung Batik Babagan merupakan salah satu sentra industri batik rumahan di Kecamatan Lasem dan menjadi tempat wisata batik dengan ciri khas sejarah dan budaya pada kawasan ini. Tersebarnya rumah produksi batik dan beberapa tempat bersejarah lainnya di kampung ini membutuhkan sebuah wadah yang dapat menjadi pusat informasi bagi para turis yang akan berkunjung. Peran arsitektur ekologis dibutuhkan 
dalam menciptakan ekosistem eco-batik di Kampung Batik Babagan Lasem sehingga dapat mewadahi kebutuhan masyarakat dalam mata pencahariannya sebagai pembatik yang meminimalisir pencemaran air, maupun memberikan sarana rekreasi sekaligus edukasi kepada turis yang dirancang sesuai dengan konteks lingkungan setempat.

\section{Tujuan}

Pusat Informasi Turis Kampung Batik Babagan Lasem dirancang sebagai solusi arsitektur ekologis dalam menciptakan ekosistem eco-batik dan menjadi wadah untuk mengakomodasi serta mengedukasi turis dan masyarakat mengenai informasi nilai sejarah dan budaya dari kawasan Babagan yang sesuai dengan konteks lingkungan setempat. Diharapkan proyek ini dapat meningkatkan ekonomi masyarakat lokal yang mata pencaharian utamanya dari membatik dengan memperhatikan dampaknya bagi lingkungan.

\section{KAJIAN LITERATUR}

\section{Arsitektur Ekologis}

Eko-arsitektur merupakan sebuah konsep rancangan bangunan yang menitikberatkan konsep nya pada bagaimana cara menghargai keberlangsungan ekosistem di alam, bukan konsep rancangan bangunan hi-tech. Pendekatan konsep rancangan ini diharapkan dapat menjaga ekosistem alam dari kerusakan yang lebih parah dan juga dapat membuat penghuni di dalam bangunan merasa nyaman baik secara fisik, social, dan ekonomi (Broadbent \& Brebia, 2006).

Eko-arsitektur bersifat kompleks, padat, dan vital, tidak menentukan apa yang seharusnya terjadi dalam arsitektur. Pendekatan ekologi arsitektur mencakup keselarasan antara manusia dan alam. Selain itu, arsitektur biologis, surya, bionik, biologi bangunan, dimensi waktu, alam, sosio-kultural, ruang dan teknik bangunan juga termasuk kedalam elemen eko-arsitektur. Oleh karena itu, eko-arsitektur merupakan istilah yang holistik dan menyangkut semua bidang (Frick \& Suskiyanto, 1998).

\section{Beyond Ecology}

Melampaui ekologi atau biasa dikenal dengan deep ecology, melihat dunia sebagai suatu kumpulan objek yang saling terhubung dan saling bergantung. Alam, manusia, dan segala sesuatunya tidak saling terpisah, namun merupakan satu kesatuan. Deep ecology memandang manusia hanya sebagai salah satu bagian dari jaringan kehidupan dan mengakui bahwa setiap makhluk hidup memiliki nilai intrinsik sehingga orientasi utama dalam mendesain bukanlah manusia (Sessions, 1995).

\section{Bahan Baku Tekstil}

Serat alami merupakan jenis serat yang diproduksi atau dihasilkan oleh tumbuhan, hewan dan proses geologis. Serat alami memiliki sifat yang mampu mengalami pelapukan karena bahan bakunya yang berasal dari alam (Fitinline, 2018) yaitu: Kapas, Sutera, Linen, Tencel.

Serat buatan manusia merupakan jenis serat yang dibuat sedemikian rupa dengan menggunakan teknik sika atau kimia sehingga serat yang dihasilkan akan memiliki sifat fisik yang sama atau justru lebih baik dari serat alami. Jenis-jenis serat buatan terdiri dari (Fitinline, 2018) yaitu: Nilon, Poliester, Akrilik, Rayon

Serat biodegradable merupakan bahan yang mampu diurai secara alami oleh mikroorganisme. Berikut diantara bahan kain yang dapat terdegradasi dengan baik (biodegradable) (Edison, 2019) yaitu: Kapas Organik, Sutra, Linen, Hemp, Jute, Poliester Daur Ulang. 


\section{Zat Pewarna Tekstil}

Zat pewarna tekstil dibagi dua berdasarkan sumber bahan bakunya, yaitu pewarna tekstil alami dan pewarna tekstil buatan. Pewarna tekstil alami berasal dari alam, seperti tumbuhan kunyit, indigofera, jalawe, teh, secang, bawang merah, kelapa, akar mengkudu, kulit buah manggis, tanaman tenggeran, tanaman tingi, dan tanaman jambal.

Pewarna sintetis (synthetic dyes) merupakan jenis zat warna yang dibuat menurut reaksi-reaksi kimia tertentu sehingga sifatnya lebih stabil dan dan mudah digunakan. Pewarnaan kain batik sendiri hanya dapat menggunakan jenis pewarna sintetis tertentu diantaranya berupa napthol, zat warna indigosol, zat warna remasol, zat warna rapid, dan zat warna direk (Fitinline, 2018).

\section{Batik}

Batik merupakan sebuah gambar yang dihasilkan dari penggunaan alat canting atau sejenisnya yang berisi lilin sebagai bahan pewarnanya. Dalam perkembangannya, batik tidak hanya dijadikan sebagai kebutuhan sandang saja, namun digunakan juga pada interior, produk cinderamata, barang mebel, dsb. Teknik pengerjaan batik juga beragam, mulai dari cara tradisional, yaitu ditulis dengan tangan maupun dengan cara modern, yaitu dengan teknik cap dan print menggunakan mesin pabrik (Rahayu, 2008).

\section{Limbah Batik}

Limbah batik terutama berasal dari limbah cair yang dihasilkan dari zat warna sisa proses pewarnaan kain, proses pencucian, dan proses pembilasan kain batik. Warna merupakan salah satu indikator pencemaran air. Pembuangan limbah cair batik berwarna tidak hanya merusak estetika perairan tetapi juga meracuni biota air. Selain itu, kepekatan warnanya menghalangi sinar matahari masuk ke dalam air sehingga menghambat proses fotosintesis air yang menyebabkan berkurangnya oksigen yang dihasilkan untuk biota air (Sianita \& Nurcahyati, 2003).

\section{Proses Pembatikan di Lasem}

Proses membatik kain di Lasem melewati proses yang panjang sehingga menghasilkan batik dengan motif dan warna yang indah. Terdapat 27 tahap pembatikan di Lasem, sbb. (Lasem, 2020):

- Nyuweki. Proses merobek bahan untuk kain panjang atau sarung.

- Nggirahi. Proses mencuci kain.

- Ngeteli. Proses memadatkan serat kain dengan minyak jarak dan soda akustik.

- Ngelorod kain ketelan, kemudian dibilas air bersih,

- Nganji kain. Kain diberi air kanji agar mudah untuk menggambar dan membatik.

- Mepe kain. Menjemur kain yang telah diberi air kanji.

- Ngemplong. Memukuli kain dengan palu kayu agar serat padat.

- Nyipati. Kai digambar garis2 miring utk kerangka membuat pola.

- Molo. Proses menggambar pola utama dengan pensil.

- Ngiseni. Melukis gambar kupu2 atau burung dengan pensil.

- Nerusi. Membatik pada bagian belakang dr sisi utama kain batik.

- Medel. Pencelupan warna merah pada kain.

- Nglengkreng. Membatik elemen2 utama pd sisi muka kain.

- Nerusi. Membatik pada bagian belakang dr sisi utama kain batik.

- Ukel Sodok. Memberi warna putih pada batik sbg isian.

- Nutul. Bagian nutul diberi motif tutul yg nantinya dibiarkan berwarna putih.

- Nemboki. Penutupan area warna merah dgn malam. 
- Bironi. Pencelupan kain utk memberi warna merah atau biro indigo.

- Nggirahi. Proses mencuci kain dengan soda lalu dijemur.

- Nemboki. Penutupan area warna biru dgn malam.

- Nyoga. Pencelupan kain ke warna coklat.

- Ngelorot. Meluruhkan malam dgn air mendidih.

- Ngebyok. Mencuci dgn gerakan keras naik turun.

- Nggirahi. Proses mencuci kain.

- Mepe kain. Menjemur kain ditempat yang berangin dan teduh.

- Nglempiti kain. Kain yg sdh dijemur dilipat dgn rapih.

- Ngepress kain. Kain di press sbg pengganti disetrika.

\section{METODE}

\section{Metode Penelitian}

Penelitian ini dilakukan pada saat pandemi. Oleh karena itu, metode yang digunakan adalah deskriptif eksploratif, yaitu dengan melakukan pengumpulan data. Pengumpulan data dilakukan dengan cara : studi pustaka/ studi literatur, data dari instansi terkait, dan browsing internet.

\section{Analisis Lokasi}

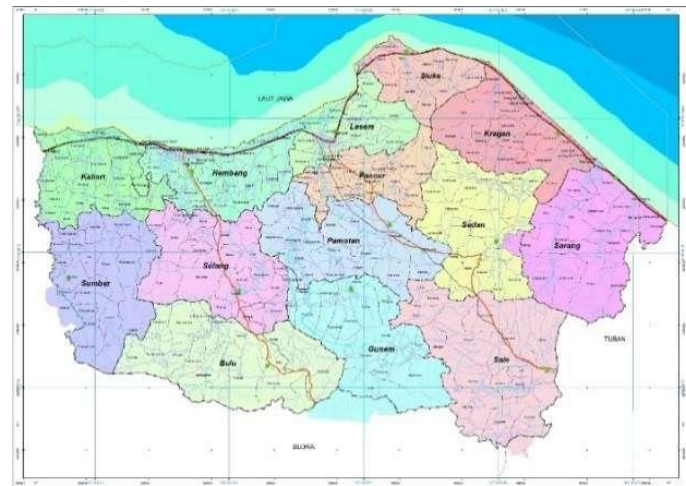

Gambar 1. Peta Kabupaten Rembang Sumber: rembangkab.go.id, 2013

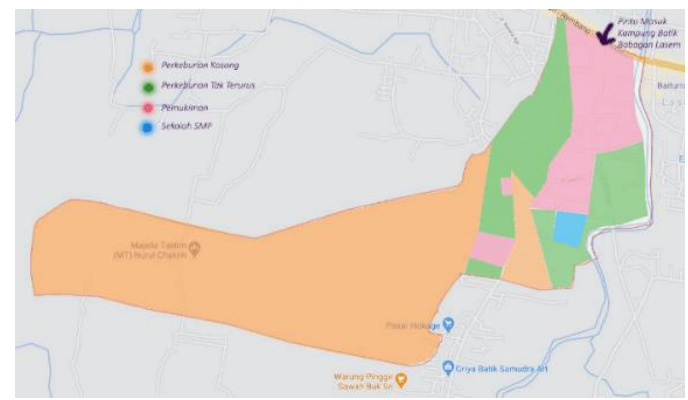

Gambar 2. Zonasi Desa Babagan

Sumber: Analisis Pribadi, 2021

Proyek mengambil lokasi di kawasan Desa Babagan, Kecamatan Lasem. Kota Lasem berada di pesisir utara Pantai Pulau Jawa dengan luas wilayah \pm 196 Ha yang tersiri dari permukiman, sawah, taman, dan kuburan. Sebelah Utara Desa Babagan berbatasan dengan Desa Gedongmulyo, sebelah Selatan berbatasan dengan Desa Karasgede, sebelah Timur berbatasan dengan Desa Karangturi, dan sebelah Barat berbatasan dengan Desa Dorokandang. 
Secara geografis, Lasem dibagi menjadi tiga wilayah, yaitu 1) Daerah yang memiliki wilayah pantai, berpusat di Caruban dan Bonang Binagun 2) Daerah dataran rendah, yang meliputi daerah pusat kota Lasem dan sekitarnya, 3) Daerah dataran tinggi atau pegunungan, meliputi gunung ngeblek, gunung idjo, gunung sertra, dsb.

Desa Babagan terletak di tepi jalan jalur Raya Pantura sehingga berpotensi berkembang ekonomi kawasannya. Selain itu, potensi di bidang perdagangan dan jasa, pariwisata, dan cagar budaya khususnya Batik Lasem merupakan beberapa aspek yang dapat mengembangkan kawasan ini. Bangunan cagar budaya, seperti Masjid dan Klenteng kuno juga masih terdapat di Desa Babagan.

\section{Arsitektur Kawasan Lasem}

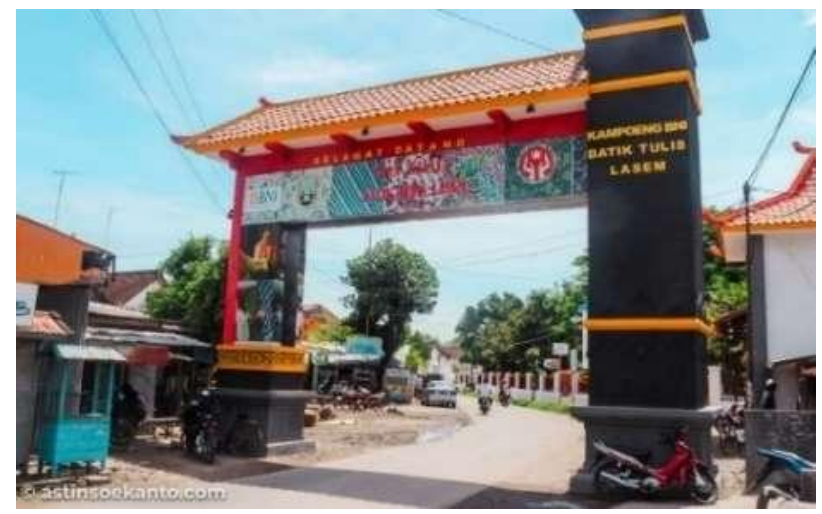

Gambar 3. Gerbang Utama Desa Babagan

Sumber: astinsoekanto.com, 2019

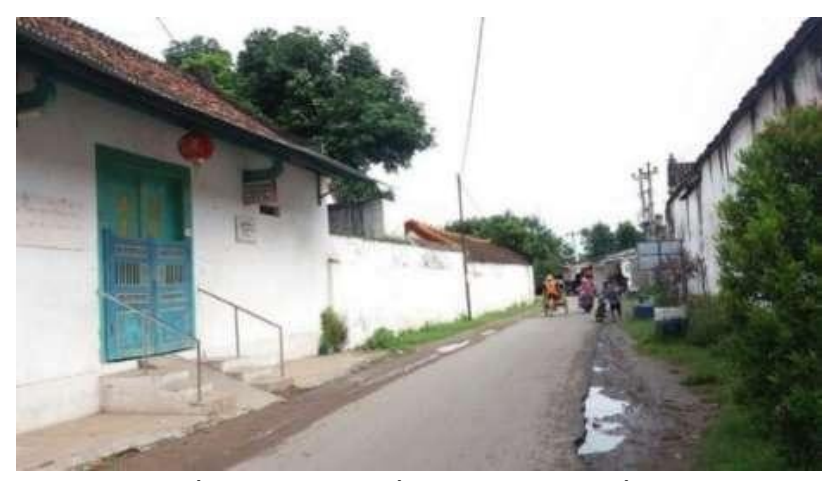

Gambar 4. Permukiman Desa Babagan

Sumber: googlemaps.com, 2019

Pada Gambar 4., massa bangunan yang ada di Desa Babagan cenderung bergaya arsitektur Cina, dapat dilihat dari beberapa fasad bangunan yang hanya terlihat dinding-dinding setinggi 3- 4 meter dan terdapat semacam gapura pada pintu gerbang utama. Hal ini dipengaruhi dari sejarah terbentuknya kawasan ini yang sangat erat dengan budaya Tionghua. Aktivitas membatik dilakukan pada siang hari sehingga jalan-jalan pada kawasan ini cenderung sepi. Lebar jalan $5 \mathrm{~m}$ diseluruh kawasan hanya dapat dilalui oleh 1 kendaraan. 


\section{Karakter Batik Lasem}

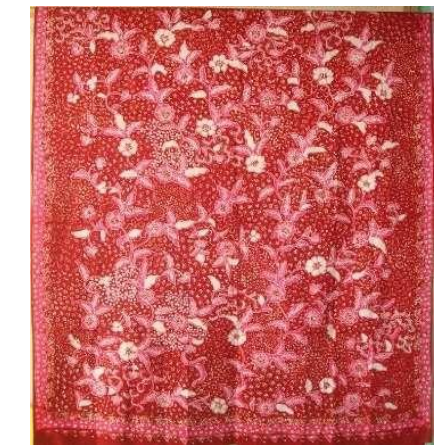

Gambar 5. Motif Sekar Jagad

Sumber: inibaru.id, 2019

Pada Gambar 5., ciri khas batik Lasem terlihat dari penggunaan warna merah yang menyerupai warna darah. Warna merah khas batik Lasem disebut dengan abang getih pithik (merah darah ayam). Warna abang getih pithik ini dihasilkan dari pewarna alam, yaitu dari warna akar pohon mengkudu (pace).

\section{Analisis Tapak}

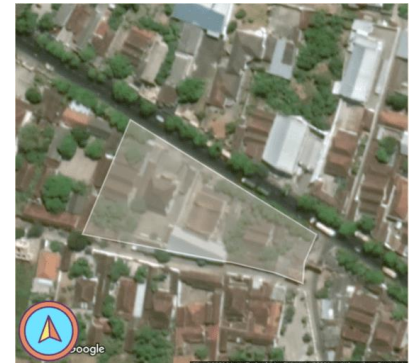

Gambar 6. Posisi Tapak Proyek

Sumber: Analisis Pribadi, 2021

Alamat : Jl. Untung Suropati No. 35/Jl. Raya Pantura, Kec. Lasem, Kab. Rembang.

Luas Tapak : $: \pm 6.607 \mathrm{~m}^{2}$

KDB $: 60 \% \quad$ KDH: $25 \%$

KLB $: 3 \quad$ GSB: $4 \mathrm{~m}$

Zonasi : Perdagangan

Eksisting : Showroom Batik, Kedai dan Warung Makanan.

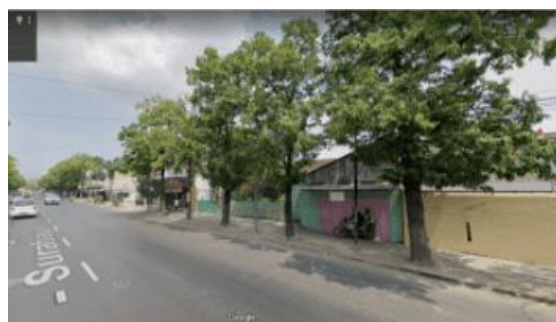

Gambar 7. Sekolah Kristen Dorkas

Sumber: googlemaps.com, 2019 


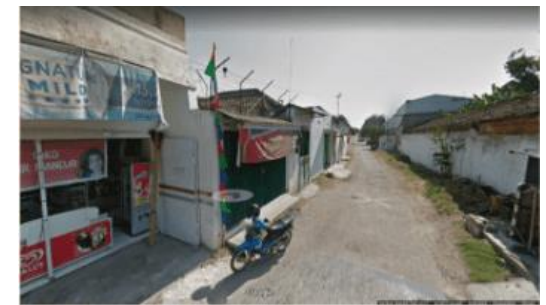

Gambar 8. Permukiman Warga Sumber: googlemaps.com, 2019

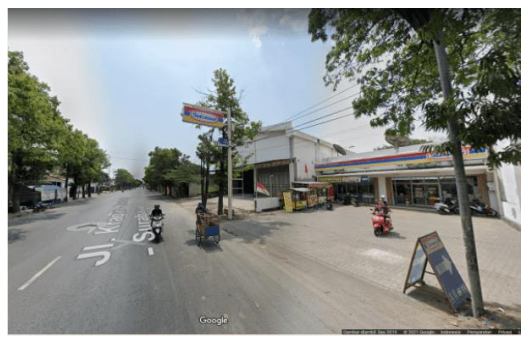

Gambar 9. Komersial

Sumber: googlemaps.com, 2019

Posisi tapak berada tepat bersebelahan dengan jalan utama yang berbatasan dengan:

Barat Laut: Sekolah Kristen Dorkas

Tenggara:jalan lingkungan, permukiman

Barat Daya: jalan lingkungan, permukiman

Timur Laut: jalan utama, komersial

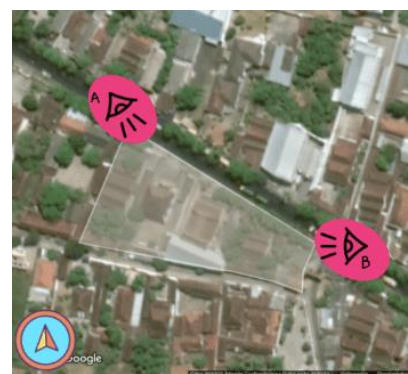

Gambar 10. View Luar ke Tapak

Sumber: Analisis Pribadi, 2021

Pada Gambar 10., terdapat view penting luar ke dalam tapak berasal dari dua arah pada jalan utama.

A-Barat Laut: view dari jalan utama tidak luas karena berbatasan dengan sekolah kristen Dorkas. B-Tenggara: view paling baik dari jalan utama karena berada di pertigaan.

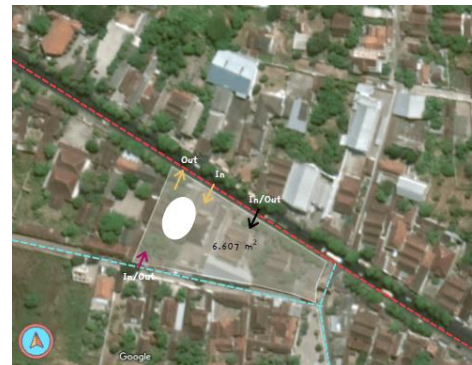

Gambar 11. Akses dan Parkir Dalam Tapak

Sumber: Analisis Pribadi, 2021 
Akses publik berupa kendaraan, yaitu bus dan mobil berada di jalan utama dan terletak di ujung tapak sehingga pengunjung sudah melewati bangunan dan dapat melihat secara keseluruhan bentuk fasad. Sedangkan, untuk akses motor berada di jalan lingkungan belakang tapak sehingga mudah diakses oleh masyarakat sekitar juga. Akses servis untuk loading dock dan pengelola serta pegawai berada di jalan lingkungan sehingga tidak bercampur dengan akses utama pengunjung.

Parkir terletak di area yang berbatasan dengan bangunan agar tidak menghalangi view dari luar ke dalam tapak. Parkir berada di lapangan untuk memudahkan akses kendaraan terutama bus yang disesuaikan dengan fungsi bangunan, yaitu sentra turis.

\section{Proses Gubahan Massa}

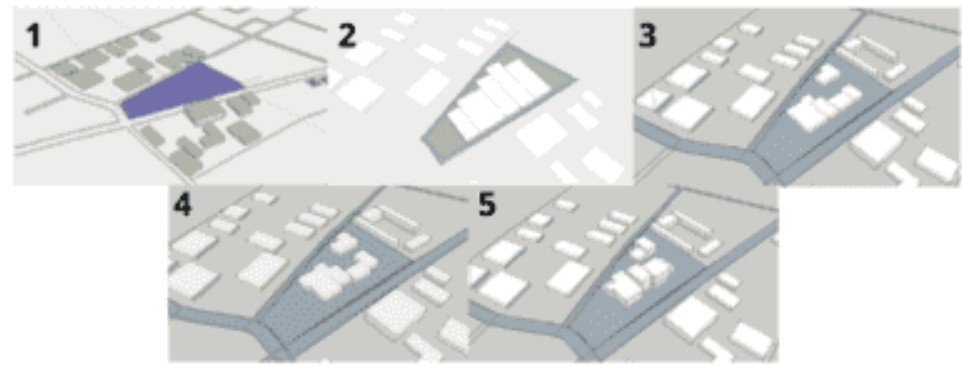

Gambar 12. Proses Gubahan Massa

Sumber: Analisis Pribadi, 2021

Massa mengambil bentuk grid sebagai pola awal, kemudian dipotong pada ujung tapak sebagai ruang terbuka hijau. Kemudian, massa dibagi menjadi dua dan ketinggiannya disesuaikan dengan fungsi program dan analisis tapak.

\section{DISKUSI DAN HASIL}
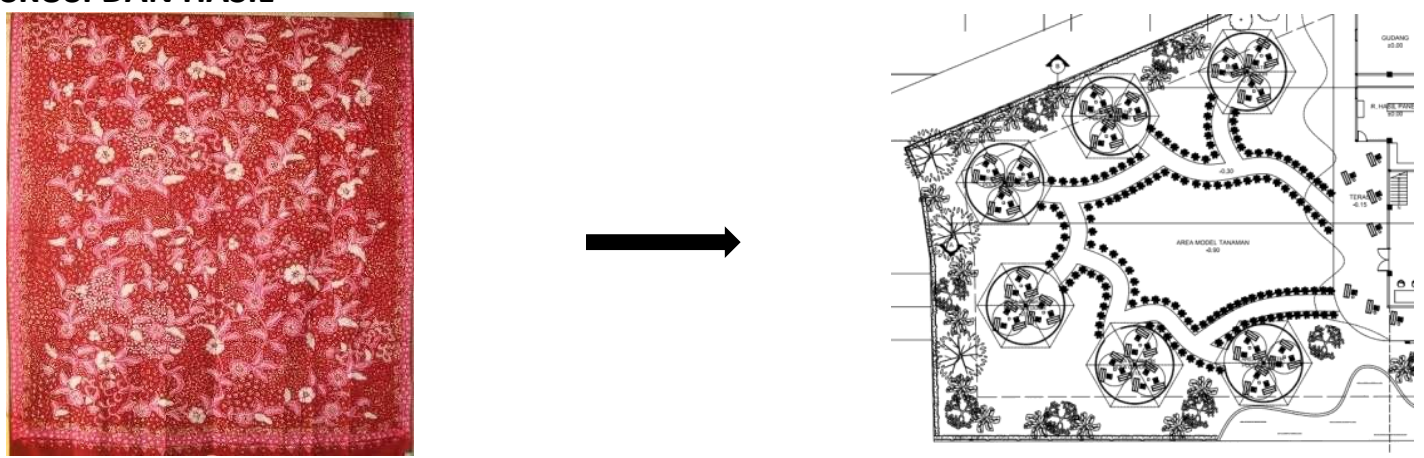

Gambar 13. Proses Gubahan Massa

Sumber: Analisis Pribadi, 2021

Penerapan motif batik Lasem dalam rancangan bangunan terdapat pada desain area membatik outdoor beserta lansekapnya. Pemisahan tiap pendopo membatik dengan tata letak yang tersebar menganalogikan bunga pada motif Sekar Jagad dan jalur yang organik sebagai tangkainya. Lansekap di antara pendopo dengan bangunan utama dimanfaatkan untuk menanam model tanaman yang menjadi bahan baku dan pewarna dari kain batik. Hal ini bertujuan agar turis mengetahui proses pembatikan dari awal hingga akhir. Peletakan zona membatik terletak di ujung kanan tapak yang letaknya paling dekat $( \pm 200 \mathrm{~m})$ dengan sungai Babagan sehingga limbah yang dihasilkan dan telah diolah dapat dialirkan lebih efisien menuju sungai. Hal ini merupakan respon dari arsitektur ekologis yang memperhatikan lingkungan sekitar. 


\section{Blokplan}

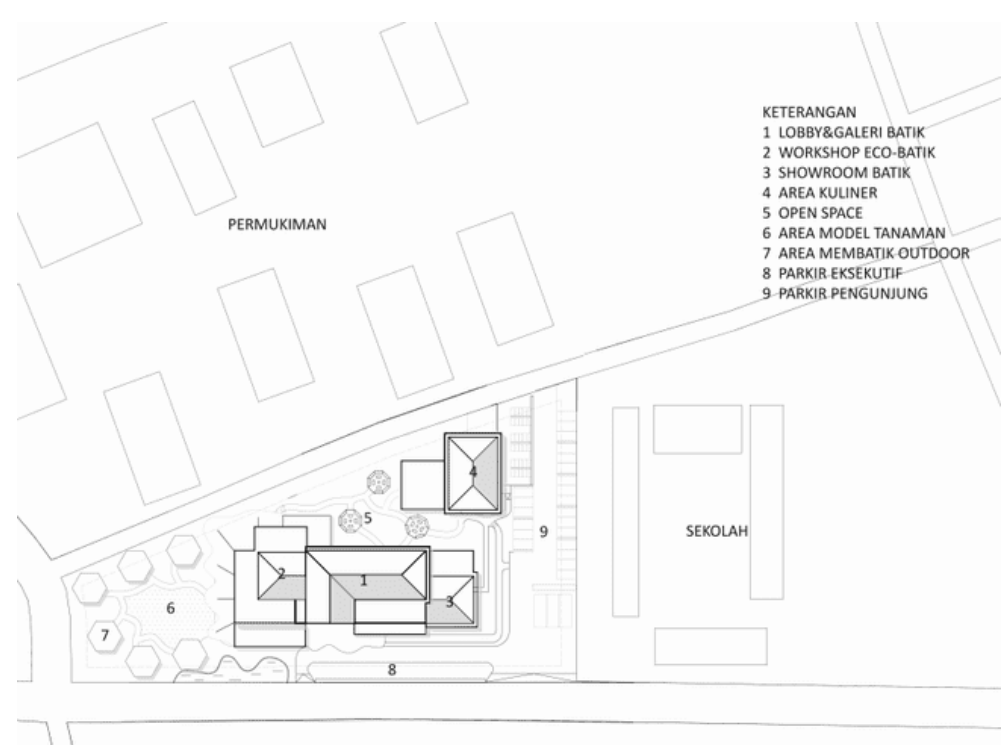

Gambar 14. Blokplan

Sumber: Analisis Pribadi, 2021

Hasil dari analisis dan sintesis tapak menjadikan massa bangunan terbagi menjadi dua, yaitu massa bangunan utama dan massa bangunan pendukung. Massa bangunan utama terletak dekat dengan jalan raya yang berisi kegiatan workshop, showroom, dan galeri batik. Sedangkan, massa bangunan pendukung terletak lebih dekat dengan perumahan warga yang berisi kegiatan area kuliner. Area parkir terbagi menjadi dua, yaitu untuk parkir umum(9) dan parkir eksekutif(8) yang digunakan untuk tamu-tamu penting.

\section{Potongan Perspektif 3D}

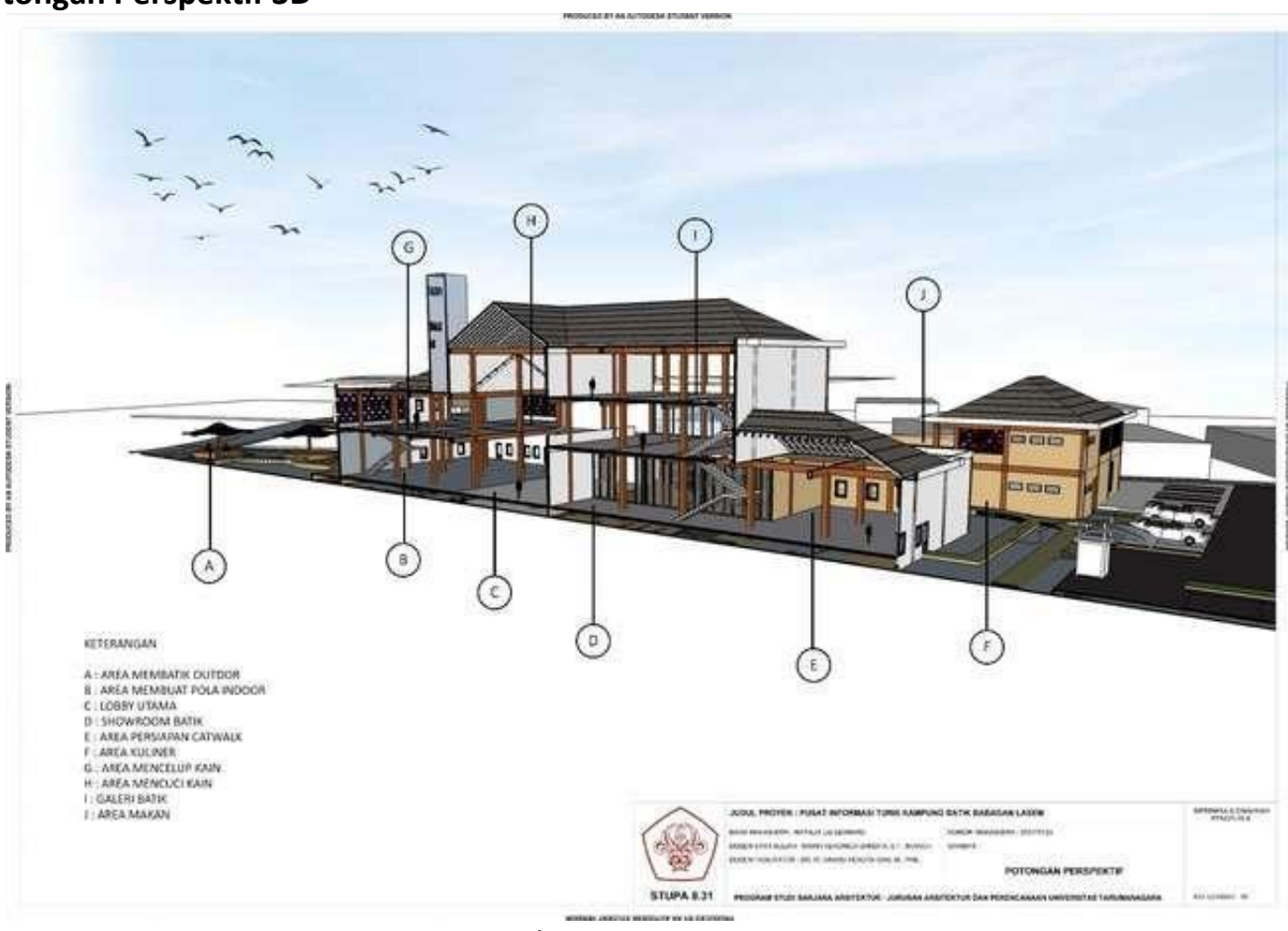

Gambar 15. Potongan 3D

Sumber: Analisis Pribadi, 2021 
Dari potongan 3D di atas, dapat dilihat bahwa lobby menjadi tempat pertama yang akan dikunjungi para turis. Disini, terdapat informasi mengenai sejarah dan persebaran rumah produksi batik sehingga turis dapat memilih untuk mengeksplor kampung batik ataupun mengeksplor kegiatan yang ada pada bangunan ini. Dari lobby, turis juga dapat berinteraksi dengan kegiatan yang terdapat pada lantai 1 maupun lantai 2 bangunan karena semuanya terhubung dengan bukaan yang tidak masif.

Pembagian ruangan untuk area workshop eco-batik berdasarkan pada proses pembuatan Batik Lasem yang melalui berbagai tahap yang dibagi secara garis besar menjadi area basah, area kering, dan area jemur. Area kering seperti membuat pola dan membatik terletak di lantai satu untuk menarik perhatian pengunjung. Sedangkan area basah seperti mencuci dan mencelup kain serta area menjemur kain terletak di lantai 2 sehingga tidak mengganggu aktivitas di lantai 1. Selain itu, area jemur kain yang terletak di balkon lantai 2 menjadi daya tarik tersendiri bagi bangunan.

\section{Zoning Isometrik Exploded}

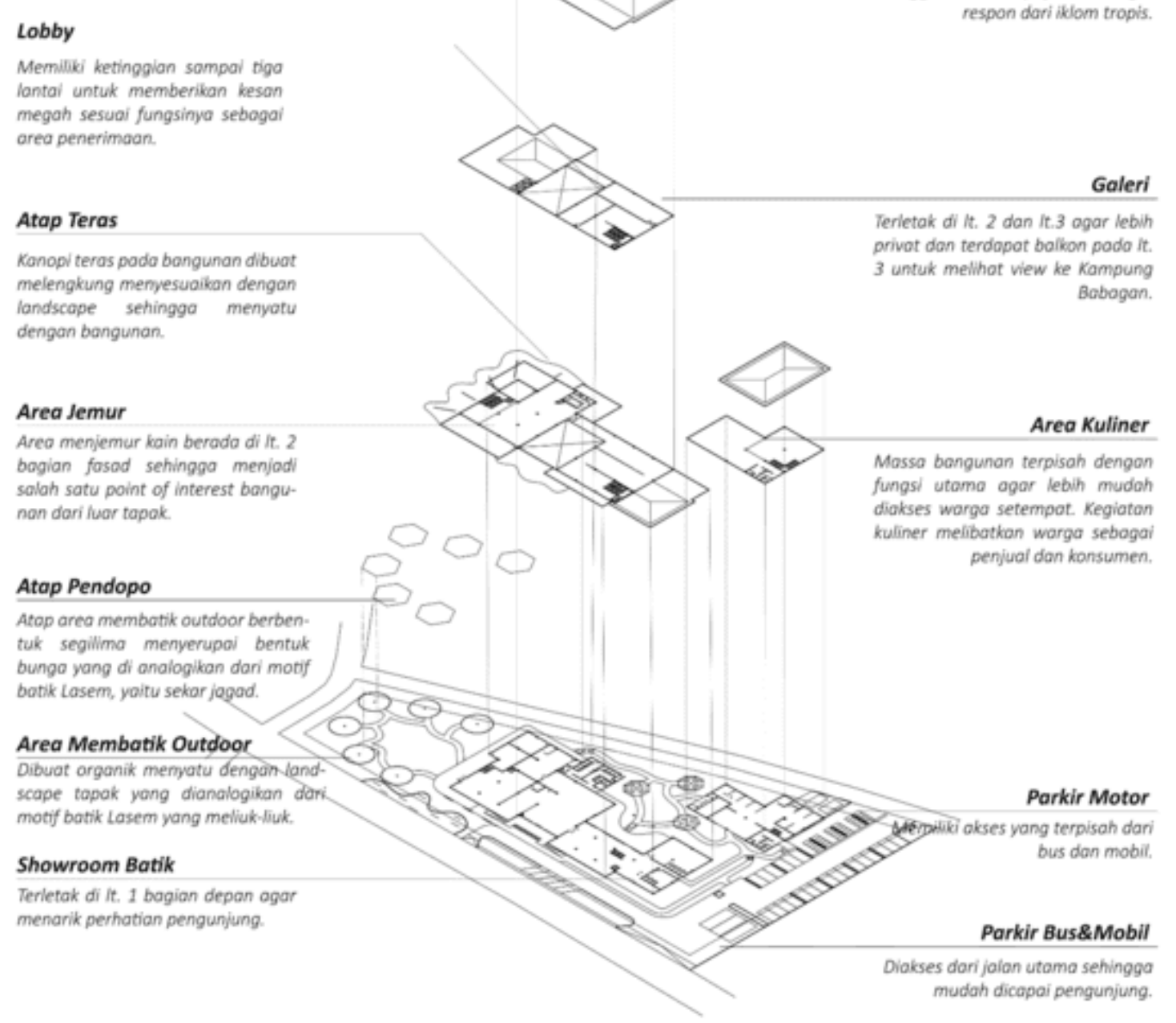

Gambar 16. Zoning Isometrik

Sumber: Analisis Pribadi, 2021 


\section{Eksterior}

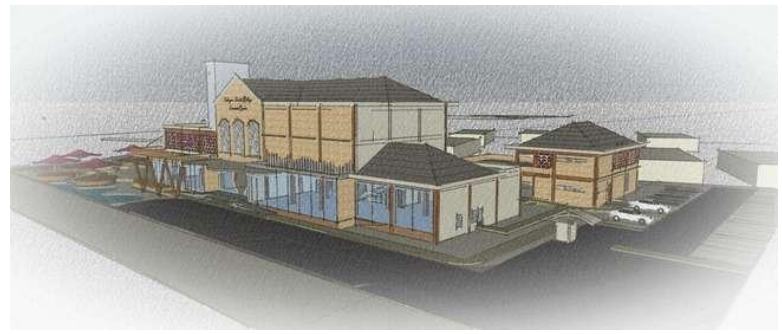

Gambar 17. Perspektif Eksterior

Sumber: Dokumentasi Pribadi, 2021

Pada fasad lantai 1 , diberi bukaan kaca sehingga kendaraan yang berlalu-lalang di jalan raya dapat melihat ke dalam dan secara garis besar aktivitas apa yang terjadi. Tempat masuk parkir terdapat di sisi kiri tapak yang berbatasan dengan bangunan lain sehingga turis yang akan mengunjungi tapak dapat mengenal dan melewati bangunan terlebih dahulu. Desain eksterior dibuat lebih modern karena menyesuaikan dengan fungsinya sebagai pusat turis yang akan menjadi tempat pertama kali pengunjung datang sehingga harus menarik perhatian. Selain itu, target pengunjung juga diperkirakan berasal dari kalangan generasi muda.

\section{Interior}

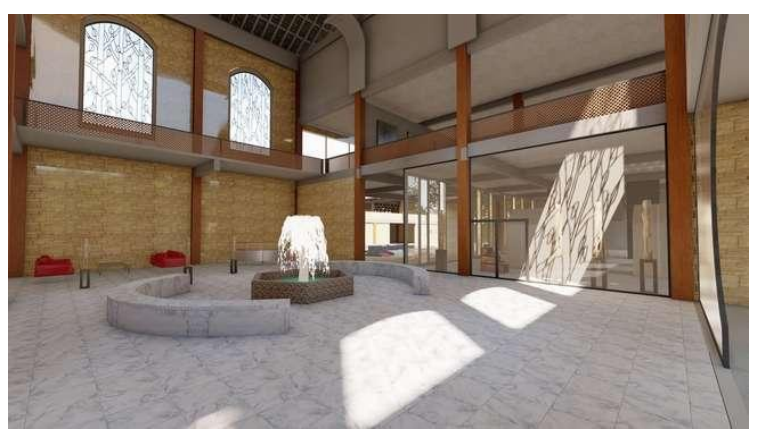

Gambar 18. Lobby

Sumber: Dokumentasi Pribadi, 2021

Lobby merupakan tempat penerimaan utama bagi para turis yang datang ke bangunan ini. Turis dapat melihat secara garis besar kegiatan apa yang ada di bangunan, yaitu showroom dan workshop eco-batik yang terdapat di lantai 1. Dari lobby turis juga dapat melihat kegiatan yang terjadi di lantai 2, yaitu adanya galeri dan area basah workshop sehingga terjadi interaksi antar pengunjung. Penerapan arsitektur Cina terdapat pada penggunaan air mancur pada area lobby yang dipercaya akan mendatangkan keberuntungan dan energi baik pada bangunan.

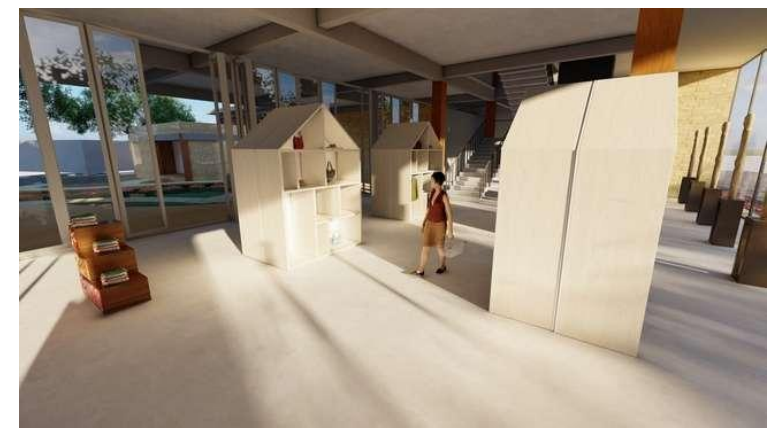

Gambar 19. Showroom Batik

Sumber: Dokumentasi Pribadi, 2021 
Pada showroom batik lantai 1, pembatas ruang dalam dan luar berupa pintu lipat kaca sehingga jika sewaktu-waktu ada fashion show batik, dapat mempergunakan area showroom sampai ke area teras. Dari showroom batik ini, pengunjung yang melihat-lihat produk juga dapat melihat ke arah courtyard di tengah tapak karena pembatas kaca tersebut.

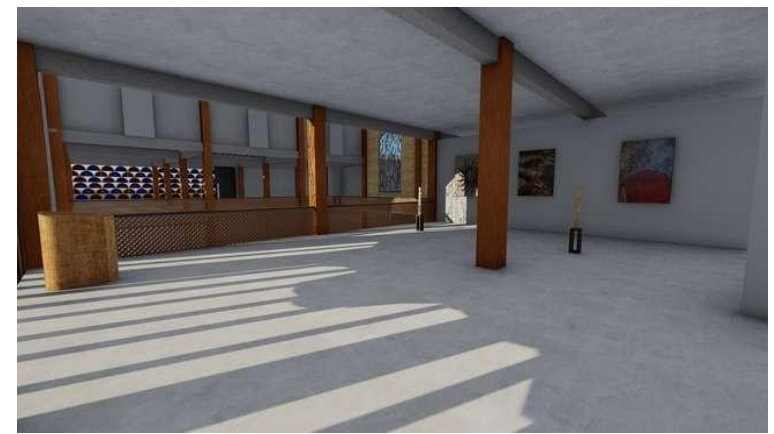

Gambar 20. Galeri Batik

Sumber: Dokumentasi Pribadi, 2021

Galeri yang terdapat pada lantai 2 bangunan dapat berinteraksi dengan kegiatan di lobby dan workshop eco-batik karena pembatas ruangannya berupa railing sehingga tidak masif.

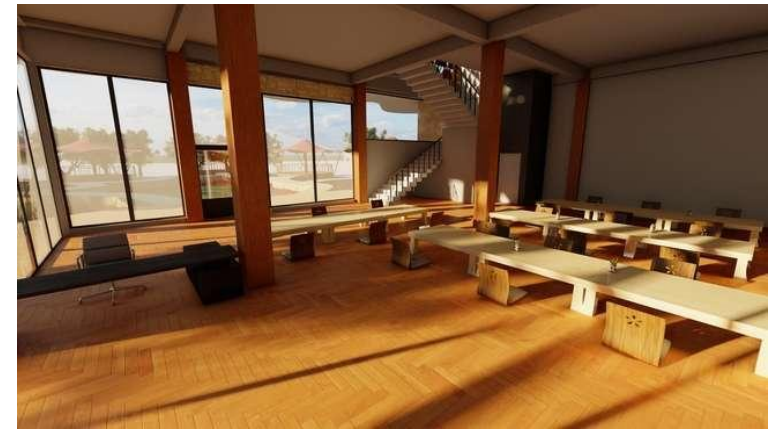

Gambar 21. Area Membuat Pola Indoor

Sumber: Dokumentasi Pribadi, 2021

Area membuat pola batik indoor terdapat pada lantai 1 sehingga aktivitasnya dapat dilihat dari luar bangunan sehingga menjadi daya tarik dari tempat ini. Untuk area membatik menggunakan lilin/malam terletak di outdoor sehingga peserta workshop dapat membatik sambil menikmati landscape tapak yang didesain menyerupai motif batik Lasem, yaitu sekar jagad.

\section{Detail Arsitektur}
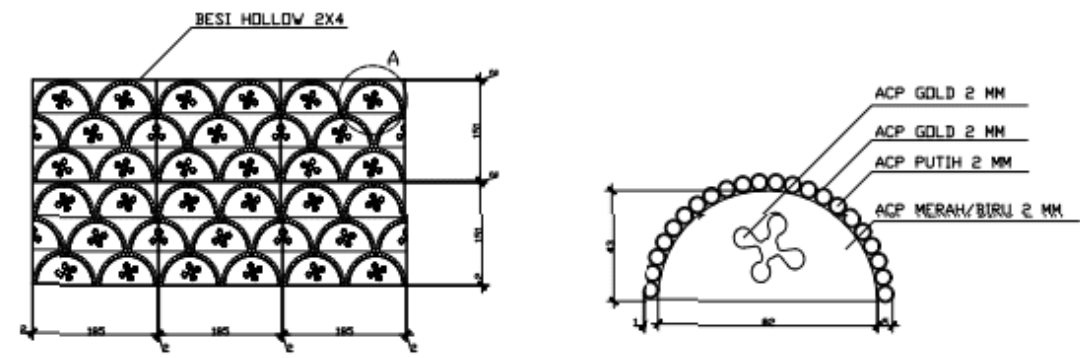

Gambar 22. Detail Tralis Batik

Sumber: Dokumentasi Pribadi, 2021 
Pada tampak bangunan, beberapa bagian menggunakan tralis motif batik Gunung Ringgit pencahayaan dan pengudaraan alami sehingga meskipun eksterior bangunan menggunakan tema modern, tetapi tetap memiliki ciri khas dari Babagan.

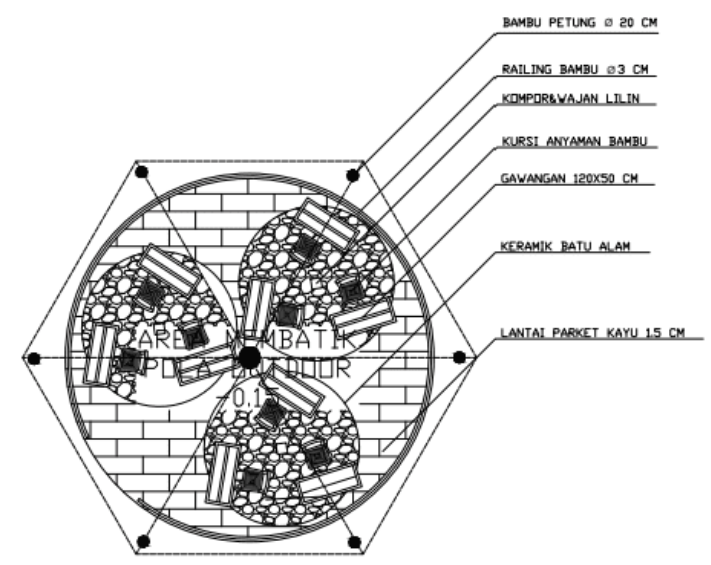

Gambar 23. Detail Pendopo

Sumber: Dokumentasi Pribadi, 2021

Area membatik outdoor terdiri dari 6 pendopo dengan kapasitas 9 orang tiap pendoponya. Area membatik dibagi menjadi tiga kelompok sehingga efisien untuk penggunaan malam/lilinnya. Material pada tiap area kelompok berupa keramik batu sehingga lebih awet saat terkena tetesan malam.

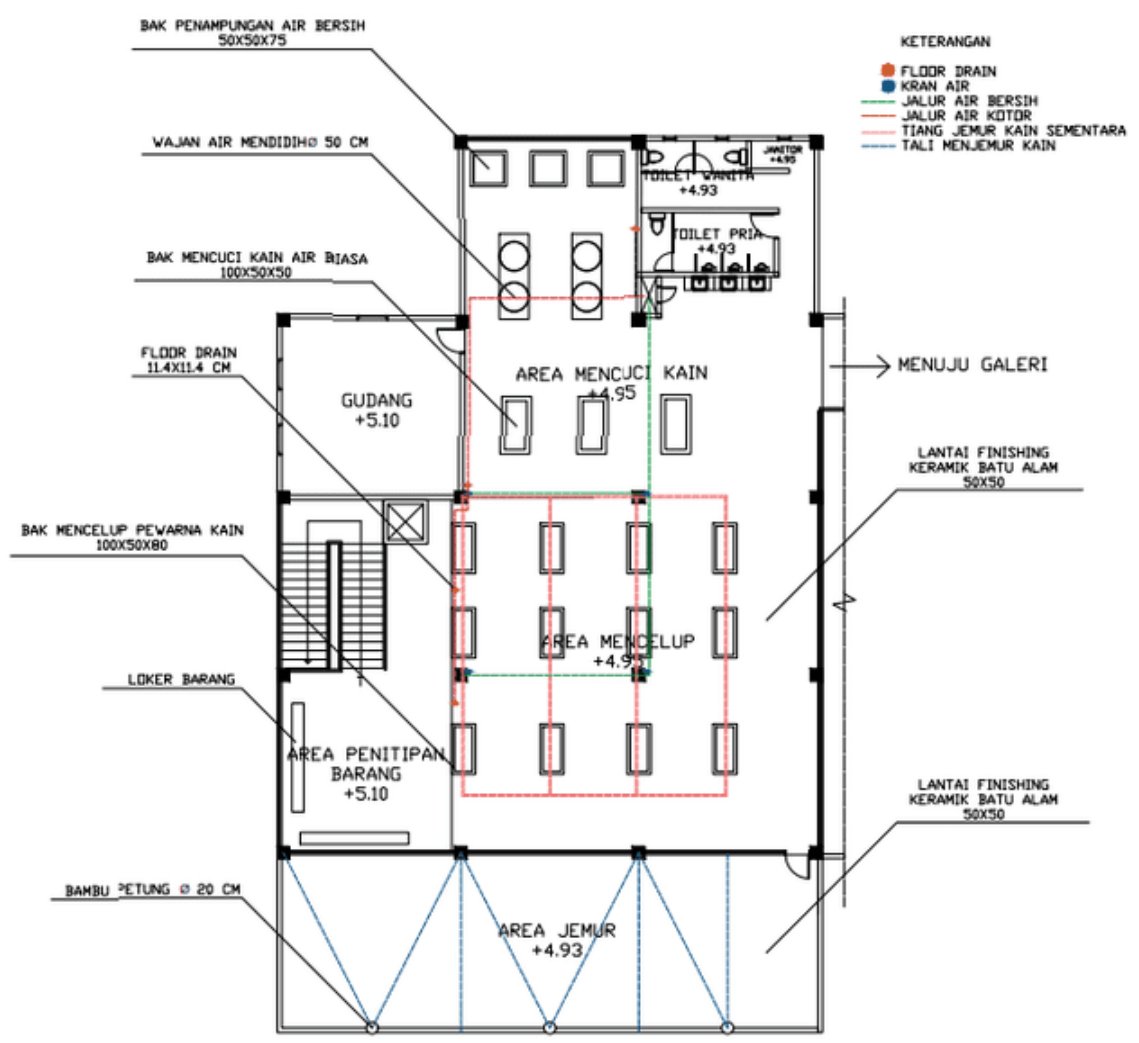

Gambar 24. Detail Area Basah Lt. 2

Sumber: Dokumentasi Pribadi, 2021 
Pada area basah workshop eco-batik yang terdapat di lantai 2, kebutuhan akan air bersih, penyaluran air bersih dan air kotor dialirkan melalui pipa yang terdapat dalam shaft. Kebutuhan tiang untuk menjemur kain sementara pada area mencelup didesain melintang diantara kolom.

\section{KESIMPULAN DAN SARAN \\ Kesimpulan}

Proyek Pusat Informasi Turis Kampung Batik Babagan dirancang untuk memenuhi kebutuhan pariwisata dan menciptakan ekosistem eco-batik yang memperhatikan ekologi. Proses kegiatan membatik membutuhkan spesifikasi dan kriteria ruangan tertentu sehingga zonasi ruang pada bangunan di rancang sesuai dengan alur proses membatik. Terdapat area model tanaman untuk memperlihatkan proses pembatikan Lasem dari awal hingga akhir. Pembuangan limbah hasil membatik diolah kemudian dialirkan ke sungai Babagan dan sebagian air digunakan kembali untuk kebutuhan bangunan.

Program Pusat Informasi Turis menjadi sebuah pusat yang mampu mengakomodasi kebutuhan turis akan informasi kampung Batik Babagan sekaligus mewadahi kebutuhan masyarakat dalam mata pencahariannya sebagai pembatik yang meminimalisir pencemaran air, maupun memberikan sarana rekreasi sekaligus edukasi kepada turis. Desain massa dibagi menjadi dua, yaitu massa utama dan massa pendukung. Landscape di desain menggunakan analogi dari motif batik sekar jaga. Atap berbentuk jurai menyesuaikan dengan iklim tropis kawasan. Detail, material, dan struktur bangunan disesuaikan dengan konteks lingkungan setempat.

\section{Saran}

Setelah melakukan penelitian, penulis menyarankan Pusat Informasi Turis Kampung Batik Babagan dibangun pada kawasan ini sehingga dapat mengakomodasi kebutuhan pariwisata dan menampilkan lokalitas masyarakat setempat yang menjadi ciri khas dari kawasan Babagan. Berbagai pendekatan yang dilakukan dalam mendesain seperti proses membatik, analisis kebutuhan kawasan dan masalah yang ada dapat menjadi acuan bagi peneliti lain yang ingin mendesain pusat turis pada sebuah kawasan. Masih banyak keterbatasan data dan batasan masalah eco-batik yang perlu dikaji lebih dalam. Oleh karena itu, perlu penelitian lebih lanjut mengenai cara penerapan eco-batik dalam desain bangunan.

\section{REFERENSI}

Broadbent, G., \& Brebia, C. (2006). Eco-Architecture: Harmonisation between Architecture and Nature. In WIT Transactions on the Built Environment (Vol. 86). WIT Press.

Edison, L. (2019, July 12). Memilih Baju yang Lebih Ramah Lingkungan.

https://kumparan.com/lampu-edison/memilih-baju-yang-lebih-ramah-lingkungan1rSGR2pstBN/full

Fitinline. (2018, November). Kenali Lebih Dalam 8 Jenis Serat Kain Alami dan Buatan Di Baju Yang Anda Pakai. Fitinline.Com. https://fitinline.com/article/read/kenali-lebih-dalam-8jenis-serat-kain-alami-dan-buatan-di-baju-yang-anda-pakai/

Frick, H., \& Suskiyanto, F. B. (1998). Dasar-dasar Eko-Arsitektur. Penerbit Kanisius.

Lasem, O. B. (2020). Batik Tulis Lasem // 29 Proses Pembu-atan Batik Tulis Tiga Negeri Lasem

// Tjoa Giok Tjiam //. https://www.youtube.com/watch?v=fLw3RrIDE5w\&t=593s

Meriastuti, E. E. (2018). PENATAAN KAMPUNG BATIK PECINAN BABAGAN LASEM SEBAGAI PUSAKA KOTA. 16. http://eprints.ums.ac.id/63807/15/NASKAH PUBLIKASI-451.pdf

Nailufar, N. N. (2020, April). Perkembangan Teknologi Produksi. https://www.kompas.com/skola/read/2020/04/17/080000969/perkembanganteknologi-produksi?page=all 
Oktaviani, P. R. (2020, September). Memanfaatkan Kain Sisa Pakaian. Media Indonesia. https://mediaindonesia.com/humaniora/343556/memanfaatkan-limbah-kain-sisapakaian

Rahayu, K. (2008). Upaya Perlindungan Batik Lasem oleh Pemerintah Kabupaten Rembang. http://eprints.undip.ac.id/18039/1/KANTI_RAHAYU.pdf

Sessions, G. (1995). Deep Ecology for The 21st Century. SHAMBHALA Boston \& London.

Setyawan, I. (2019). Pengertian Batik : Definisi, Cara, Corak, Budaya, Jenis, Macam ! https://umbelen.com/pendidikan/seni-budaya/pengertian-batik/

Sianita, D., \& Nurcahyati, I. S. (2003). Kajian Pengolahan Limbah Cair Industri Batik, Kombinasi Aerob Anaerob Dan Penggunaan Koagulan Tawas. In Laporan Penelitian, Semarang, Fakultas Teknik Universitas Diponegoro. 